Cell Research (2003); 13(1):59-68

http://www.cell-research.com

\title{
Identification of ABA-responsive genes in rice shoots via cDNA macroarray
}

\author{
Fang LIN*, Shou Ling XU*, Wei Min NI, Zhao Qing CHU, Zhi Hong XU, Hong Wei XUE** \\ National Laboratory of Plant Molecular Genetics, Institute of Plant Physiology and Ecology, Shanghai Institutes \\ for Biological Science (SIBS), Chinese Academy of Sciences; and Partner Group of Max-Planck-Institute of Mo- \\ lecular Plant Physiology (MPI-MP) on "Plant Molecular Physiology and Signal Transduction", 300 Fenglin \\ Road, 200032 Shanghai, China
}

\begin{abstract}
Phytohormone abscisic acid (ABA) was critical for many plant growth and developmental processes including seed maturation, germination and response to environmental factors. With the purpose to detect the possible ABA related signal transduction pathways, we tried to isolate ABA-regulated genes through cDNA macroarray technology using ABA-treated rice seedling as materials (under treatment for 2, 4, 8 and $12 \mathrm{~h}$ ). Of $6144 \mathrm{cDNA}$ clones tested, 37 differential clones showing induction or suppression for at least one time, were isolated. Of them 30 and 7 were up- or down-regulated respectively. Sequence analyses revealed that the putative encoded proteins were involved in different possible processes, including transcription, metabolism and resistance, photosynthesis, signal transduction, and seed maturation. 6 cDNA clones were found to encode proteins with unknown functions. Regulation by ABA of 7 selected clones relating to signal transduction or metabolism was confirmed by reverse transcription PCR. In addition, some clones were further shown to be regulated by other plant growth regulators including auxin and brassinosteroid, which, however, indicated the complicated interactions of plant hormones. Possible signal transduction pathways involved in ABA were discussed.
\end{abstract}

Key words: Oryza sativa, abscisic acid (ABA), cDNA macroarray, responsive genes, signal transduction

\section{INTRODUCTION}

ABA (abscisic acid), an important growth regulator during plant growth and development, has been demonstrated to be involved in many plant developmental processes, especially seed development including maturation and germination, and plant response to environmental factors. It has shown that ABA was accumulated rapidly during plant seed development or under the stress condition of water deficiency, salt and cold conditions and further induced the expressions of the related genes to improve the resistance of plants[1-3], or through the

* These authors contribute equally to the paper.

**Corresponding author: Tel: 0086-21-64042090 ext 4411

Fax: 0086-21-64042385 E-mail: hwxue@iris.sipp.ac.cn

Received July-26-2002 Revised Jan-14-2003 Accepted Jan-28-2003 regulation of $\mathrm{PKABA}$, encoding a kind of protein kinase, and Gamyb to effect the ABA and GA antagonism during seed germination[4]. Studies by means of genetic and molecular technologies have resulted in the identification of ABA-regulated genes and corresponding transcription factors necessary for ABA-related signal transduction (for review, see [5],[6]). Up to now, 6 genes, shown to be necessary for the ABA-related signal transduction have been reported and their encoded proteins were classified as 2 transcription factors (VP1 of maize and ABI3 of Arabidopsis[7],[8]), 2 members of highly conserved protein phosphatase 2C family[9-11], 1 transcription regulator harbouring APETALA 2 domain (ABI4[12]) and 1 farnesyl transferase (ERA1 of Arabidopsis[13]). Studies have been focused on the 
physiological roles of $\mathrm{ABA}$ and its related signal transduction[5]. However, the complication of ABA signal network made it relatively difficult to isolate and analyze ABA-regulated genes with traditional methods[14]. Even until now, much was still unknown about the functional mechanism of ABA, especially the related signal transduction in plant cells.

The recently developed cDNA microarray technology enabled monitoring of cell-, tissue- and developmental stage-specific gene expression profiles and simultaneous quantitative analyses of expression levels of genes[15-19], which could help people to further find out new genes possibly involved in the same process or signaling pathway. This will help people to have the general and full knowledges on certain developmental processes. cDNA microarray technology has also been used in plant research field for gene studies in recent years[20]. Schena et al. first experimentally made the array with 45 Arabidopsis genes and successfully detected the difference of low expressed genes[21]. Through this technology, Reymond et al. analyzed 150 wounded and insect-related genes of Arabidopsis[22], and Grike et al. analyzed genes related to seed development of Arabidopsis and found $25 \%$ and $10 \%$ of the genes tested, in total 2600 arrayed genes, increased 2 and 10 times respectively during Arabidopsis seed development[23]. Seki et al. analyzed expression patterns of 1300 Arabidopsis full-length cDNAs under cold and drought conditions, and found 44 drought- and 19 cold-induced cDNAs, in which 30 and 12 , respectively, were newly reported[24]. They also found 12 genes were induced by transcription factor DREB1A (dehydration-response element binding protein) and further analyses showed that drought response elements were present in these 12 genes. All these results suggest that cDNA microarray would be useful not only for isolation of new genes, which would certainly help people to study the general profiles of the tissue-specific or environment related cDNAs, but also for identification of target genes and potential cis elements of transcription factors.

We are interested in the ABA related signal transduction and its function mechanism in plants. Here we report, based on the comparison of the differences of gene expression patterns through cDNA macroarray technology, the isolation and identification of $\mathrm{ABA}$ regulated genes in rice. We hope this would possibly provide some hints for the mechanisms on ABA mediated signal transduction in plant cells.

\section{MATERIALS AND METHODS}

\section{Materials}

ABA (abscisic acid) was obtained from Sigma (USA). 96-well PCR plates were from ABGENE and 96-well cell plates were from Nunc. Taq polymerase and standard T3 and T7 primers were from Sangon (Shanghai, China). dNTP were obtained from TaKaRa Biotechnology (Dalian, China). Radiochemical $\left[\alpha-{ }^{33} \mathrm{P}\right]$ dCTP was obtained from ICN (Meckenheim, Germany). RNA reverse transcription labeling kit was obtained from GIBCO-BRL (USA). Primers for reverse transcription PCR (RT-PCR) were obtained from TIB Molbiol (Berlin, Germany).

\section{Bacteria and plant materials}

Escherichia coli JM109 cells were used for amplifying the cDNA library. Cells were cultivated at $37^{\circ} \mathrm{C}$ in LB medium supplemented with appropriate antibiotics using standard methods[25]. Oryza sativa cv. Zhonghua 11 were germinated on $1 / 2 \mathrm{MS}$ medium and grown in water in phytotron with a $12 \mathrm{~h}$ light $\left(26^{\circ} \mathrm{C}\right)$ and 12 -h dark $\left(18{ }^{\circ} \mathrm{C}\right)$ period.

\section{$A B A$ treatment and RNA isolation}

2 week old rice seedlings (grown in water) were treated with 100 $\mu \mathrm{M}$ ABA for 2, 4, 8, $12 \mathrm{hrs}$ and then frozen in liquid nitrogen for further analysis. Total RNA was prepared according to the extraction procedures of acid guanidinium thiocyanate-phenol-chloroform[25] with few modifications: $1 \mathrm{~g}$ seedlings (including same amounts of treated materials for different time scales) were powdered in liquid nitrogen, extracted with guanidinium thiocayanatephenol-chloroform, then precipitated with ethanol and purified with $\mathrm{LiCl}$ and chloroform each time. Total RNA, suspended in RNase-free water finally, was stored at $-70^{\circ} \mathrm{C}$ after spectrophotometrical quantification at $260 \mathrm{~nm}$.

\section{cDNA library construction and macroarray preparation}

Collected ABA treated materials were used for plasmid cDNA library construction using pBluescript vector by TaKaRa Biotechnology (Dalian, China). Titers of the cDNA library were calculated based on the white colonies obtained under the white/blue selection on the plate supplemented with isopropylthio- $\beta$-D-galactoside (IPTG) and X-Gal after transferred to E. coli cells via electroporation.

A total of 6144 white colonies from the library were randomly chosen from the plates (supplemented with appropriate concentration of ampicillin, X-Gal and IPTG) and cultured overnight in 
96-well cell plates. cDNA insertions were then amplified with standard $\mathrm{T}_{3}$ and $\mathrm{T}_{7}$ primers in 96-well PCR plate with T-gradient PCR instrument (Biometra Company, Götingen, Germany) using E. coli culture as templates. $\mathrm{PCR}$ reactions were performed in a total

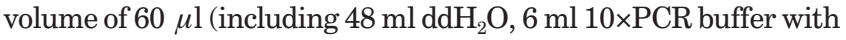
$15 \mu \mathrm{M} \mathrm{MgSO}_{4}, 2.5 \mu \mathrm{l} 2.5 \mathrm{mM}$ dNTP, $2 \mathrm{ml} 20 \mathrm{pM}$ primers, $0.5 \mu \mathrm{l} \mathrm{Taq}$ polymerase and $1 \mu \mathrm{lE}$. coli culture as template) as follows: $94^{\circ} \mathrm{C}$ for $3 \mathrm{~min}, 1$ cycle; then with 40 cycles of $94^{\circ} \mathrm{C}$ for $1 \mathrm{~min}, 52^{\circ} \mathrm{C}$ for 1 $\min , 72^{\circ} \mathrm{C}$ for $3 \mathrm{~min}$; and finally with an extension at $72^{\circ} \mathrm{C}$ for 10 min. PCR products were checked on $1 \%$ agarose gel by electrophoresis.

Nylon membranes (Hybond, Amersham) was precut and wetted with $2 \times$ SSC for DNA spotting. PCR products were arrayed on nylon membranes using Biomek 2000 HDRT system (Beckman, Fullerton, CA, USA) with the spotting procedures as follows: spotting needles stayed for 2 sec in DNA samples (in 96-well PCR plate) and $2 \mathrm{sec}$ on nylon membranes, then $5 \mathrm{sec}$ in $\mathrm{ddH}_{2} \mathrm{O}$ twice for washing, $5 \mathrm{sec}$ in $75 \%$ ethanol and dried for 10 sec. DNA samples were spotted in $4 \times 4$ array and each sample was duplicated on crossway which resulted in the 1536 DNA spots $(16 \times 96)$ standing for $768 \mathrm{cDNA}$ clones on each membrane. After spotting membranes were then denatured $(0.5 \mathrm{M} \mathrm{NaOH}, 1.5 \mathrm{M} \mathrm{NaCl})$ for 1-5 min, neutralized (1.5 M NaCl, 0.5 M Tris.Cl, $\mathrm{pH} 7.4$ ) for $5 \mathrm{~min}$ and washed with $2 \times \mathrm{SSC}$ for $2-5 \mathrm{~min}$, and then incubated at $80^{\circ} \mathrm{C}$ for 2 $\mathrm{h}$ for stabilization of DNA on the membranes.

\section{Hybridization and image analyses}

$5 \mathrm{mg}$ rice total RNA, extracted from ABA-treated (for 2 and 8 h) and untreated 2-week-old rice seedlings, respectively, was labeled with $\left[\alpha{ }^{33} \mathrm{P}\right] \mathrm{dCTP}$ through reverse transcription using RNA labeling kit (GIBCO-BRL, USA). Resulted products were quantified with liquid scintillation counting (Beckman LS6500, USA) and the labeled first strand cDNA with same amounts of radioactivities were used as hybridization probes. Hybridization was performed at $65^{\circ} \mathrm{C}$ for more than $40 \mathrm{~h}$ in $250 \mathrm{~m} \mathrm{M}$ sodium phosphate buffer pH7.2 containing 7\% SDS, $1 \%$ BSA, and $1 \mathrm{~m} \mathrm{M}$ EDTA. Washes were performed at $65^{\circ} \mathrm{C}$ in $2 \times \mathrm{SSC}, 0.1 \% \mathrm{SDS}$ for 15 $\mathrm{min}, 1 \times \mathrm{SSC}, 0.1 \% \mathrm{SDS}$ for $15 \mathrm{~min}$ and $0.2 \times \mathrm{SSC}, 0.1 \% \mathrm{SDS}$ for 20 $\min [26]$. After overnight exposure, the images of membrane were scanned using phosphoimager (FUJIFILM, Japan) and resulted profiles were analyzed with commercial image processing system AIS program (Imaging Research INC., USA). As each sample was spotted on the membrane with duplication, signals acquired were calculated in the average of each clone for further comparison. After twice hybridizations using independent treated samples, differential expressed cDNA clones with the ratio (treated/control) > 1.5 or $<0.5$ were selected and sequenced for further analyses.

\section{Reverse transcription PCR (RT-PCR) analysis}

RT-PCR analyses were carried out to confirm the ABA regulation of selected clones revealed by cDNA macroarray. $5 \mathrm{mg}$ total $\mathrm{RNA}$, isolated form ABA-treated (for 0, 2, 4, 8 and $12 \mathrm{~h}$ ) rice seedlings was reverse transcribted to first strand cDNAs using oligo (dT) primer in a total volume of $40 \mu$ l according to supplier's instruction (SuperScript Pre-amplification System, Promega). Resulted cDNAs were then used as templates for PCR amplification in a volume of $30 \mu \mathrm{l}$ as follows: $94^{\circ} \mathrm{C}$ for $3 \mathrm{~min}$; then $30-35$ cycles of $94^{\circ} \mathrm{C}$ for $40 \mathrm{sec}, 56^{\circ} \mathrm{C}$ for $40 \mathrm{sec}, 72^{\circ} \mathrm{C}$ for $45 \mathrm{sec}$; and finally with an extension at $72^{\circ} \mathrm{C}$ for $10 \mathrm{~min}$. Primers used for the selected clones in RT-PCR were listed in the Tab 1. The rice Rac1 actin coding gene was used as positive internal control with primers RAc1-1 and 2 (Tab 1). Amplified PCR products (10 $\mu \mathrm{l}$ ) were electrophoresed on a $2.5 \%(\mathrm{w} / \mathrm{v})$ agarose gel and monitored using the Gel Doc 2000 (Bio-Rad Company, USA).

Tab 1. Primers used in reverse-transcription PCR

\begin{tabular}{cl}
\hline No. of Clones & \multicolumn{1}{c}{ Primers sequences (5'-3') } \\
\hline Xd469 & 1: ggAgAAAggACTgAgTTAgC \\
& 2: TggATggACCTACCTgCATg \\
Xd422 & 1: AgAgTgCTgAggCTgTTgAg \\
& 2: CCAgACAgTACTAgCATAAgC \\
Xd514 & 1: gCACAgggATTACTCTCACCg \\
& 2: TggCCCTCTCCAAgAATAAgCTC \\
Xd502 & 1: ACATggCggACCAgCTCTCC \\
& 2: gAAgAggATAgAggAgAAAg? \\
Xd478 & 1: CATTCATgAgCTTCAggTgCTg \\
& 2: gTggATTTCgTCCATATCTACg \\
Xd450 & 1: CTgAAgCCCgTACCCCACAcg \\
& 2: gAAACTgCCCggTACCACAAgg \\
Xd439 & 1: CTgTCAACgACgACgAgggCATg \\
& 2: gCTTgCTgCTTACTgCTgCgC \\
Rice-actin & 1: gAACTggTATggTCAAggCTg \\
(Rac1) 2: ACACggAgCTCgTTgTAgAAg
\end{tabular}

\section{ESULTS}

\section{cDNA library construction and macroarray preparation}

Plasmid cDNA library using vector pBluescript was constructed with $100 \mu \mathrm{M}$ ABA-treated (for 2, 4, 8 and $12 \mathrm{~h}$ ) rice seedlings and harboured a total of $3 \times 10^{5}$ white colonies under white/blue selection. cDNA insertions were amplified via PCR using standard T3 and T7 primers and results showed that the sizes of insertions were between $0.5-3 \mathrm{~kb}$, in 1 . $2 \mathrm{~kb}$ average. A total of $6144 \mathrm{PCR}$ products representing same numbers of independent clones randomly chosen from plates were arrayed on 8 nylon membranes, on which there were 1536 DNA samples (in a $4 \times 4$ array) spotted on each membrane for 768 cDNA clones with duplication on the crossway (Fig 1A) to ensure the results reproducible. 
A

C

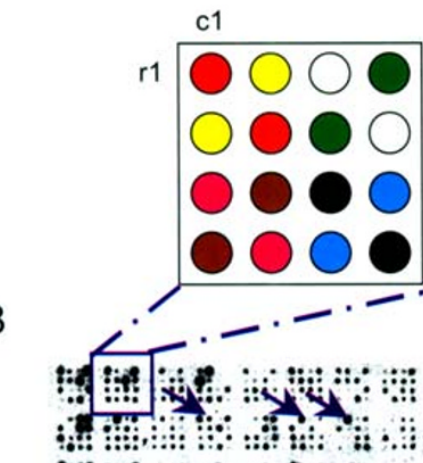

\begin{tabular}{|c|c|c|c|c|}
\hline 1st & 2nd & C.K. & ABA & ABA/C.K. \\
\hline R4-C9 & r2-C4 & 0.0262 & 0.1072 & 4.0916301 \\
\hline R4-C9 & r2-C4 & 0.0484 & 0.1295 & 2.6756198 \\
\hline R4-C9 & r2-C4 & 0.0599 & 0.1434 & 2.39399 \\
\hline R4-C9 & r2-C4 & 0.0678 & 0.1482 & 2.1858407 \\
\hline R4-C9 & r2-c2 & 0.0580 & 0.1094 & 1.8862069 \\
\hline R4-C9 & r2-c3 & 0.0658 & 0.1116 & 1.6960486 \\
\hline R4-C9 & r2-c3 & 0.1040 & 0.1702 & 1.6365385 \\
\hline
\end{tabular}

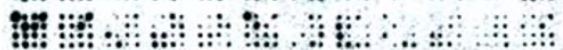

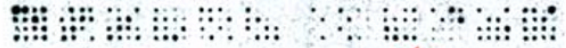
象

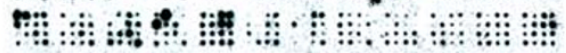

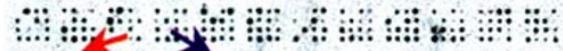

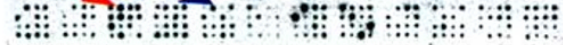

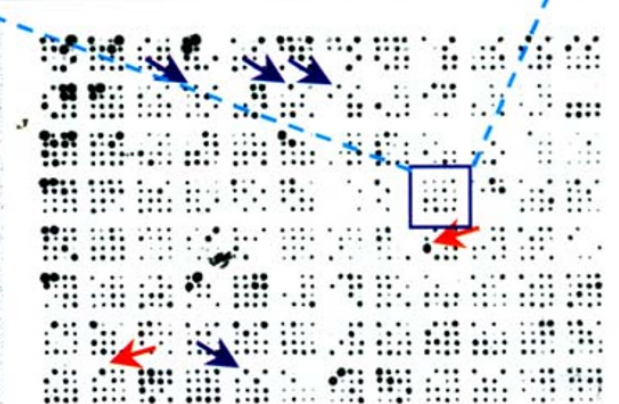

D

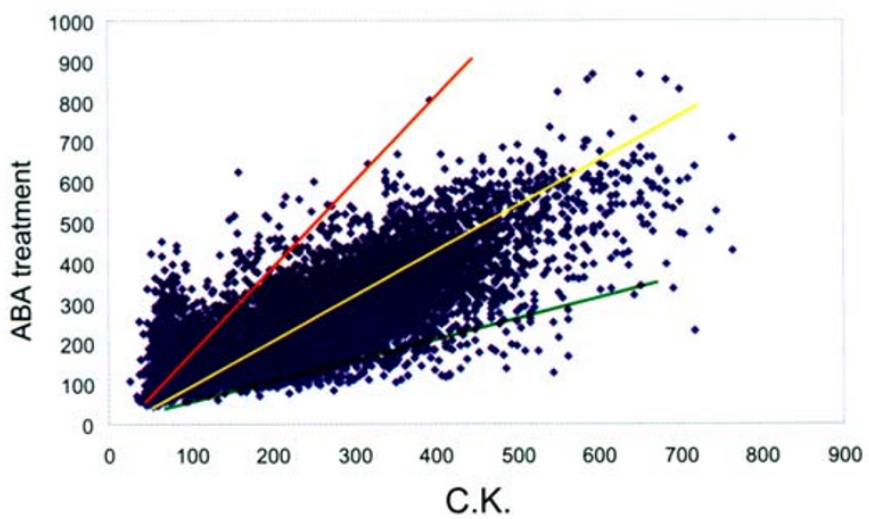

Fig 1. cDNA macroarray and image analyses A. PCR products were arrayed on the nylon membranes in a 4\&time;4 array. Each sample was duplicated on crossway; B. A typical image of cDNA macroarray after hybridization, red and blue arrows indicate up- and down-regulated clones respectively, left-control; right-ABA treated; C. Images were analyzed with “AIS" program. Image signals were transferred to digital characteristics for comparison between treated and control samples resulting in the regulation ratio. $\quad$ D. Most of the samples analyzed are within the ratio 0.5-2.0. Ratio was calculated through treated/control (in average) and ratio 0.5 (green), 1.0 (yellow) and 2.0 (red) were marked.

\section{Hybridization and isolation of rice ABA-regulated} genes

Rice total RNAs, extracted from ABA-treated (for 2, 4, 8 and $12 \mathrm{~h}$ ) and untreated control materials (using liquid culture medium), were labeled with $[\alpha-$ $\left.{ }^{33} \mathrm{P}\right] \mathrm{dCTP}$ through reverse transcription. Resulted labeled first strand cDNA were quantified with liquid scintillation counting and same amounts of labelled cDNAs were used as probes for hybridization. Resulted images, as shown in Fig 1B, were then analyzed with AIS software through transferring the image signals to digital characteristics for 
Tab 2. Characteristics of ABA-regulated genes in rice shoots through cDNA macroarray analysis (Id. Identities; Po. Positives). Rice shoots were treated with $100 \mu \mathrm{M}$ ABA for 2 and $8 \mathrm{~h}$. (Clones isolated before were indicated as "reported" and those not isolated before were as "new" The nucleotide sequences have been submit ted to GenBank ${ }^{\mathrm{TM}} / \mathrm{EMBL}$ Data Bank with shown accession numbers).

\begin{tabular}{|c|c|c|c|c|c|c|}
\hline \multicolumn{7}{|c|}{ ABA-up-regulated genes } \\
\hline No & Acc. Nos & Homologous genes & Species & Homology & $\begin{array}{cc}\text { Ratio } & 1 \\
\mathrm{ABA} / \mathrm{CK} & \mathrm{R}\end{array}$ & $\begin{array}{c}\text { New or } \\
\text { Reported } \\
\text { in rice }\end{array}$ \\
\hline $\mathrm{Xd} 435$ & AF017362 & Putative fructose-bisphosphate aldolase & O. sativa & Id.97\%; Po.97\% & $2.17 \pm 0.20$ & New \\
\hline $\mathrm{Xd} 409$ & AJ457802 & DnaJ protein homolog & Glycine $\max$ & Id.84\%; Po.91\% & $2.12 \pm 0.15$ & New \\
\hline $\mathrm{Xd} 469$ & AJ437267 & histidine kinase homolog & A. thaliana & Id.45\%; Po.60\% & $2.11 \pm 0.36$ & New \\
\hline $\mathrm{Xd} 404$ & AJ457803 & bZIP transcriptional activator homolog & Arabidopsis thaliana & Id.44\%; Po.56\% & $2.10 \pm 0.14$ & New \\
\hline $\mathrm{Xd} 454$ & AJ441302 & Remorin homolog & S. tuberosum & Id.41\%; Po.51\% & $2.03 \pm 0.28$ & New \\
\hline $\mathrm{Xd} 500$ & AJ429043 & Cytochrome b5 homolog & Nicotiana tobacum & Id.49\%; Po.66\% & $1.98 \pm 0.37$ & New \\
\hline $\mathrm{Xd} 514$ & AJ437338 & Sphingosine kinase homolog & A. thaliana & Id.40\%; Po.52\% & $1.95 \pm 0.52$ & New \\
\hline $\mathrm{Xd} 422$ & $\mathrm{AB} 017042$ & Glyoxalase I & O. sativa & Id.100\%;Po.100\% & $1.96 \pm 0.02$ & New \\
\hline $\mathrm{Xd} 477$ & AJ437533 & myosin heavy chain homolog & A. thaliana & Id.39\%; Po.56\% & $1.91 \pm 0.20$ & New \\
\hline \multirow[t]{2}{*}{$\mathrm{Xd} 481$} & AJ439989 & Ribulose-bisphosphate carboxylase small & & & & \\
\hline & & chain homolog & O. sativa & Id.68\%; Po.71\% & $1.91 \pm 0.14$ & New \\
\hline $\mathrm{Xd} 491$ & AJ437538 & Polyubiquitin 6 homolog & Petroselinum Hill & Id.95\%; Po. & $1.87 \pm 0.27$ & New \\
\hline $\mathrm{Xd} 511$ & AJ428900 & Myb-family transcription factor & A. thaliana & Id.51\%; Po.62\% & $1.87 \pm 0.01$ & New \\
\hline $\mathrm{Xd} 496$ & AF094776 & $\begin{array}{l}\text { Chlorophyll a/b-binding protein type } \mathrm{Ib} \text {, } \\
21 \mathrm{~K} \text { chain homolog }\end{array}$ & Hordeum vugare $L$. & Id.89\%; Po.92\% & $1.82 \pm 0.23$ & New \\
\hline $\mathrm{Xd} 426$ & X57325 & Basic/leucine zipper protein & Oryza sativa & Id. $81 \% ;$ Po. $81 \%$ & $1.82 \pm 0.02$ & Reported \\
\hline $\mathrm{Xd} 408$ & AJ437266 & RNA helicase hor & A. thaliana & Id.68\%; Po.78\% & $1.79 \pm 0.05$ & New \\
\hline $\mathrm{Xd} 480$ & AJ437534 & Proline-rich protein homolog & G. $\max$ & Id.40\%; Po.53\% & $1.76 \pm 0.03$ & New \\
\hline $\mathrm{Xd} 504$ & AJ441303 & RNA helicase homolog & A. thaliana & Id.50\%; Po.63\% & $1.73 \pm 0.23$ & New \\
\hline $\mathrm{Xd} 502$ & AF231026 & Calmodulin homolog & O. sativa & Id.68\%; Po.70\% & $1.71 \pm 0.15$ & New \\
\hline $\mathrm{Xd} 478$ & AJ439992 & WD-repeat protein-like homolog & A. thaliana & Id.55\%; Po.76\% & $1.70 \pm 0.02$ & New \\
\hline $\mathrm{Xd} 423$ & AJ439991 & Phytoene synthase homolog & Zea mays & Id.95\%; Po.97\% & $1.65 \pm 0.05$ & New \\
\hline $\mathrm{Xd} 487$ & AJ437264 & $\begin{array}{l}\text { Triose phosphate/3-phosphate } \\
\text { translocator homolog }\end{array}$ & Z. mays & Id.87\%; Po.93\% & $1.64 \pm 0.64$ & New \\
\hline \multirow[t]{2}{*}{$\mathrm{Xd} 458$} & AJ437532 & Ferric leghemoglobin reductase isoenzy & yme & & & \\
\hline & & homolog & G. $\max$ & Id. 83 & $1.63 \pm 0.12$ & New \\
\hline $\mathrm{Xd} 461$ & $\mathrm{X} 13909$ & Chlorophyll a & G. $\max$ & Id.70\%; Po.71\% & $1.63 \pm 0.02$ & New \\
\hline $\mathrm{Xd} 405$ & AJ437265 & Putative asparaginyl endopeptidase & O. sativa & Id.73\%; Po.78\% & $1.55 \pm 0.00$ & New \\
\hline $\mathrm{Xd} 418$ & AJ441304 & amino acid acetyltransferase homolog & A. thaliana & Id.68\%; Po.87\% & $1.55 \pm 0.05$ & New \\
\hline $\mathrm{Xd} 450$ & $\begin{array}{l}\text { AJ439990 } \\
\text { AB011367 }\end{array}$ & LIP9 -cold acclimation protein & O. sativa & Id.68\%; Po.72\% & $1.54 \pm 0.03$ & Reported \\
\hline $\mathrm{Xd} 494$ & - & Unknown & & & $2.31 \pm 0.25$ & New \\
\hline $\mathrm{Xd} 464$ & - & Unknown protein & & & $2.24 \pm 0.07$ & New \\
\hline $\mathrm{Xd} 498$ & - & Unknown protein & & & $1.90 \pm 0.06$ & New \\
\hline $\mathrm{Xd} 459$ & - & Unknown protein & & & $1.67 \pm 0.07$ & New \\
\hline \multicolumn{7}{|c|}{ ABA-down-regulated genes } \\
\hline $\mathrm{Xd} 526$ & AJ441305 & Putative proline synthase associated protein & A. thaliana & Id.59\%; Po.68\% & $0.44 \pm 0.05$ & New \\
\hline $\mathrm{Xd} 448$ & AJ437536 & cytochrome P450 homolog & Lotus japonicus & Id.49\%; Po.64\% & $0.43 \pm 0.03$ & New \\
\hline $\mathrm{Xd} 439$ & AJ437339 & Ethylene-responsive protein 2 homolog & Hevea brasiliensis & Id.55\%; Po.60\% & $0.41 \pm 0.01$ & New \\
\hline $\mathrm{Xd} 441$ & AJ293816 & MADS box transcription factor homolog & S. tuberosum & Id.41\%; Po.59\% & $0.40 \pm 0.06$ & New \\
\hline $\mathrm{Xd} 445$ & AJ437537 & $\begin{array}{l}\text { PhotosystemII associated-manganese- } \\
\text { binding protein PsbY homolog }\end{array}$ & Spinacia oleracea & Id.38\%; Po.46\% & $0.39 \pm 0.10$ & New \\
\hline $\mathrm{Xd} 525$ & - & Unknown protein & & & $0.48 \pm 0.00$ & New \\
\hline Xd434 & - & Unknown protein & & & $0.31 \pm 0.02$ & New \\
\hline
\end{tabular}


detecting the differences between treated samples and control (Fig 1C). As each clone was spotted on the membrane with duplication, digital characteristics acquired were analyzed with control in the average with ratio (treated/control) to test the induction or suppression, i.e. $<2.0$ or $<0.5$ indicated the induction or suppression of the corresponding clones with one time level respectively. Hybridizations were repeated for two times using independent treated samples. As shown in Fig 1D, most of the samples (around $93 \%$ of the total clones) tested were located in a range between 2.0 and 0.5 that indicated no response to ABA for most of the samples under 2$12 \mathrm{~h}$ ABA treatment. Thus, samples with the ratio $>1.5$ (for detailed analysis with a extension from 2 . 0 to 1.5 ) or $<0.5$ comparing to control were picked out and original cDNA insertions were sequenced. In a total of 6144 arrayed cDNA clones, after sequencing, 41 were found to be regulated by $\mathrm{ABA}$, in which 31 and 10 were found to be up- and downregulated respectively. Sequences of these 41 clones were then analyzed with BLAST program against database and 32 of them shared homologies with known proteins and 6 of them with unknown functions. The putative proteins encoded by identified clones were classified as different families involved in transcription (encoding bZIP, MADS, Myb transcription factors), metabolism and resistance (encoding transferase, synthase and kinase), photosynthesis, signal transduction (encoding kinase, calmodulin and WD-repeat proteins), and seed development. Results were shown in Tab 2.

Among the identified clones, some cDNAs have been reported from rice, including phytoene synthase and putative bZIP (basic/leucine zipper) transcription factors coding genes, have been demonstrated to be induced under stress situations [27] and cold stress[28],[29]. Most of them were not reported before.

\section{Confirmation of $A B A$ regulation with selected clones}

Some clones, which encoded putative proteins involved in signal transduction, seed development or metabolism, were chosen for further RT-PCR analyses (primers used were shown in Tab 1) to confirm the ABA regulation. To confirmed the materials used were in parallel and especially avoid of the affection of circadian regulation, control plants (at exactly identical time scales with treatment) and treated rice seedlings were used for RNA extraction and further RT-PCR analysis. In total tested 7 clones, which encoded putative ethylene-inducible protein (AJ437339), cold accumulation protein (Lip9) (AJ439990), sensory transduction histidine kinase (AJ437267), WD-repeat protein (AJ439992), glyoxalase I (AB017042), calmodulin (AF231026) and sphingosine kinase (AJ437338), as shown in Fig 2, were detected to be regulated by ABA. The regulation tendencies of these clones fit the ratio results

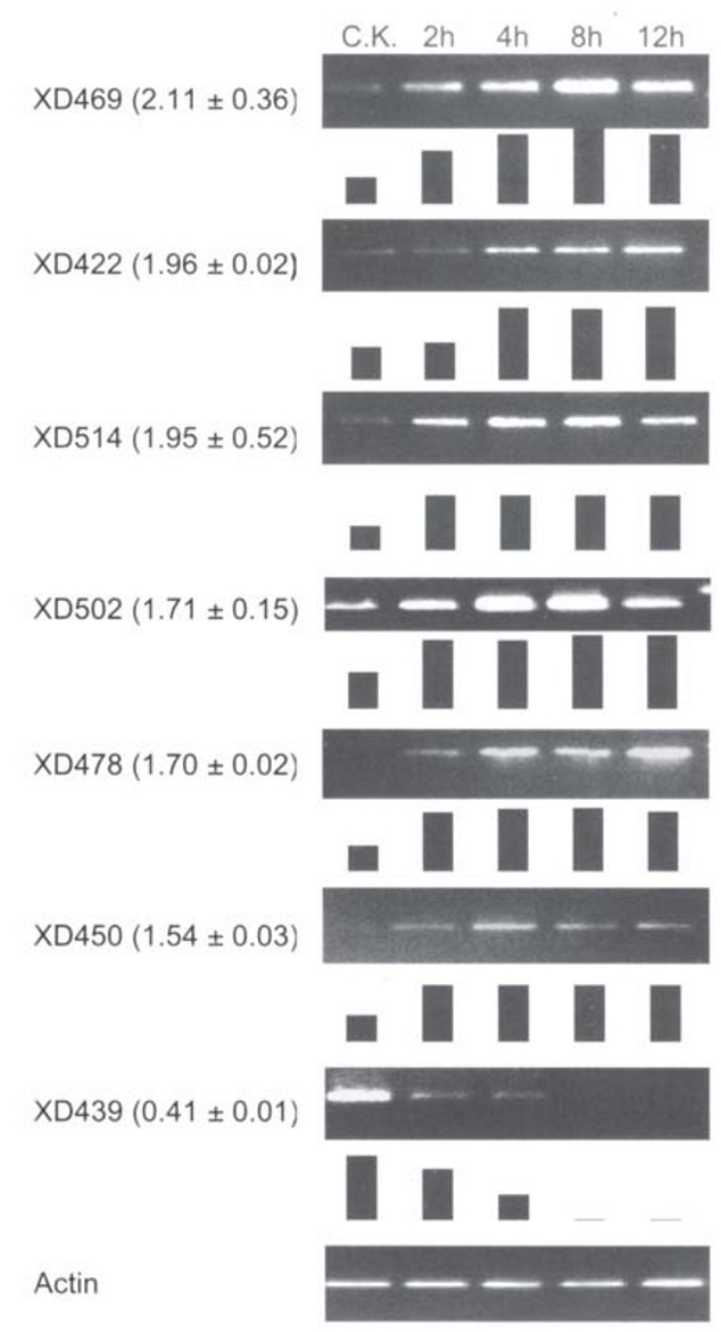

Fig 2. Confirmation of ABA regulation of selected clones through RT-PCR. Samples were collected after ABA treatment for $0,2,4,8$ and $12 \mathrm{~h}$. Primers used were shown in table 1 . Numbers showed the ratio of the selected clones comparing to control after hybridization and analyzed with "AIS" program. Bottom line showed the photodensity of the DNA products. Rice Rac1 gene was used as internal control. 
obtained from macroarray.

\section{DISCUSSION}

\section{cDNA macroarray and hybridization}

cDNA microarray technology has been shown to be powerful to analyze expression profiles of numbers of genes in parallel so as to find out new genes in specific tissue and organs or during specific growth and developmental stages, or under different conditions such as cold, salt stress, drought and pathogen infection[30], [31]. One advantage of this technology was the possibility to find out the genes related to one process or developmental stage in one experiment in genome scale, this would certainly provide informations for the complicated network of signal transduction[32]. However, the cost for microarray experiment performance is very expensive. Although the density of spots in a certain space is less and quality of nylon will have more affection in the hybridization results than microarray, macroarray will be cheaper and convenient for general lab performance. Since some steps may affect the macroarray results, including the array spotting, hybridization and evaluation of the results. To overcome the possible problems, we first spotted the DNA samples into different membranes at same time to be sure the amounts of DNA with same samples spotted on different membranes are identical so that the comparison after hybridization was believable, and spotted the same sample with duplication to confirm the results; second, quantified the hybridization probes after labeling with liquid scintillation counter to be sure the radioactivities used during hybridization were identical to make the signals acquired comparative; and third, evaluated the image signals to digital characteristics to compare the differences more precisely.

In the experiments reported in this paper, 6144 cDNA clones, which possibly stand for the $10 \%$ or more cDNAs of rice were arrayed and tested, which provided the possibility to isolate genes related to ABA signaling pathways from rice in genome scale. Amplification of cDNA insertions with standard primers made it relatively easier to perform the amplification in large scales and the following spotting of PCR products. Hybridization of the arrayed nylon membranes using $\left[{ }^{33} \mathrm{P}\right] \mathrm{dCTP}$ labeled first strand
cDNAs (same amounts of radioactivities of treated samples and control) was performed parallelly after reverse transcription and the following analyses with AIS program would be helpful for finding out the differentially expressed clones. This was demonstrated, as shown in Fig 1d, that most of the clones tested within the range $0.5-2.0$ in ratio.

\section{$A B A$ regulated genes}

Genes selected from macroarray, which provide hints for differential expressed gene isolation, still need further confirmation through either Northern blot or RT-PCR analysis. Sequence analyses and homologous searches indicated that some clones, identified by cDNA macroarray, were indeed regulated by environmental factors, which suggested the possible relation to $\mathrm{ABA}$ and the involvement in ABA-related signal transduction pathways. Protein encoded by clone Xd423 shared high homology (95\%) to maize phytoene synthase, which was demonstrated to be induced under stress situations (Steinbrenner and Linden, 2001). Protein encoded by clone Xd426 (X57325), a basic/leucine zipper transcription factor, was shown to be induced under cold treatment[28],[29]. However, confirmation of the identified clones is still required. RT-PCR results, however, $30 \%$ of clones (3 of 10) tested did not give PCR products, which might be due to the reason by PCR itself.

\section{Possible ABA related signaling pathways}

Most of the clones identified by cDNA macroarray were unknown or unreported to be related or involved in ABA mediated signal transduction before. Based on RT-PCR confirmation for some clones related to different signal transduction pathways, we may suggest that some genes were involved in ABA mediated signaling pathways for stress response.

WD-repeat protein was demonstrated to be involved in many signal transduction pathways[33-35] including SPA (inhibitor of PhyA[36]) and TRIP1 (subunit of eIF3, interacted with TGF- $\beta$ receptor, and may involve in the brassinosteroid stimulated plant growth[37]). A putative ABA induced WD-repeat protein, with $64 \%$ identities ( $80 \%$ homologies) to an Arabidopsis one[4],[33], was indeed regulated by ABA.

Histidine kinase plays a role in many signal 
transduction pathways[38-40] Histidine kinase domain was found in phytochrome and related to rhymes[41]. The recently reported CKI1, receptor of cytokinin in Arabidopsis, was a histidine kinase. Sphingosine kinase, together with phospholipase C, phospholipae D and MAPK, were involved in the cell response to environmental stimuli including growth factors, cytokinin, G-protein coupled stimulator and so on[40],[42-44]. Up-regulation of rice histidine kinase and sphingosine kinase by ABA treatment may suggest their roles in $\mathrm{ABA}$ function.

Cold accumulation protein: ABA increased rapidly under cold stress and further induced related gene expression for plant resistance. Cold-induced gene, Kin2, isolated from Arabidopsis, was induced by ABA, salt and drought[45]. A putative rice cold accumulation protein was isolated and confirmed to be induced by ABA treatment, which shared $72 \%$ and $52 \%$ homologies with rice and wheat cold accumulation protein Lip9 and WCOR410b.
Additionally, protein encoded by clone Xd481 (AJ439989) shared 68\% homologies to rice ribulose1,5-bisphosphate carboxylase/oxygenase (Rubisco), which catalyzed the reaction of oxygen and ribulose1,5-bisphosphate resulting the production of glycerate-3-phosphate and glycolic acid-2-phosphate. $\mathrm{CO}_{2}$ and $\mathrm{NH}_{3}$ were produced during the conversion of glycolic acid-2-phosphate to glycine. This reaction could prevent the overreduction of photosynthetic electron transport chain in light respiration under stress situation so as to prevent the light inhibition. Furthermore, glycine, the metabolite of photorespiration, is the precursor of the synthesis of glutathione, which also play a role in the responses of plant cells to environmental stress[46]. Induction of the expression of small chain precursor of Rubisco under ABA treatment may suggest that under stress condition, increase of the Rubisco would stimulate the plant photorespiration, reduce the photoinhibition and result in the plant self

Tab 3. Clones regulated by both $\mathrm{ABA}$ and auxin or brassinosteroids through cDNA macroarray. Auxin (IAA, $100 \mu M$ ) treatment was performed with 2-week rice shoots for 2 and $12 \mathrm{~h}$ and brassinosteroids (24epi-brassinolide, $10 \mu M$ ) treatment was performed with 2 -week rice shoots for 4 and $24 \mathrm{~h}$.

\begin{tabular}{llcccl}
\hline \multirow{2}{*}{ No. } & Acc. No. & \multicolumn{2}{c}{ Ratio under treatment } & \\
\cline { 3 - 5 } & & ABA & BR & IAA & \\
\hline Xd491 & AJ437538 & $1.87 \pm 0.27$ & - & 2.825 & Polyubiquitin 6 \\
Xd448 & AJ437536 & $0.43 \pm 0.03$ & - & 0.416 & Putative cytochrome P450 \\
Xd445 & AJ437537 & $0.39 \pm 0.10$ & - & 0.404 & PhotosystemII associated- manganese-binding protein PsbY precursor \\
Xd441 & AJ293816 & $0.40 \pm 0.06$ & - & 0.382 & Probable MADS box transcription factor \\
Xd458 & AJ437532 & $1.63 \pm 0.12$ & 3.581 & - & Ferric leghemoglobin reductase isoenzyme 2 precursor \\
Xd454 & AJ441302 & $2.03 \pm 0.28$ & 2.792 & - & Remorin \\
Xd480 & AJ437534 & $1.76 \pm 0.03$ & 2.743 & - & Proline-rich protein precursor \\
Xd409 & AJ457802 & $2.12 \pm 0.15$ & 2.676 & - & DnaJ protein homolog \\
Xd477 & AJ437533 & $1.91 \pm 0.20$ & 2.592 & - & Probable myosin heavy chain \\
Xd494 & - & $2.31 \pm 0.25$ & 2.655 & - & Unknown protein \\
Xd434 & - & $0.31 \pm 0.02$ & 0.397 & - & Unknown protein \\
\hline
\end{tabular}

protection.

\section{Interaction of $A B A$ with auxin and $B R s$}

It should be noticed that the cross talk between different signaling pathways were widely present in plant cells, especially on hormone regulated pathways. We hereby performed the analysis on the same samples under treatment with other hormones, i.e. auxin and brassinosteroid (Shen et al., submitted; Chu et al., submitted). Results of expression pro- files showed that some clones, regulated by ABA, were regulated by IAA or BR as well (Tab 3). The possible multi-regulated clones encoded putative cytochrome P450, MADS box transcription factor, Proline-rich protein precursor, seed maturation protein and so on. Together with the results that ethylene-response protein was regulated by ABA (Fig 2, clone Xd439, AJ437339), although the detailed analysis on the regulation by both hormones is still required, these may indicate the complicated inter- 
actions of signal pathways with different hormones. For example, polyubiquitin expressed at variable amounts in many plant tissues with high levels in metabolically active and/or dividing cells, vascular tissues and was induced by wound, heat, or ethylene treatments[47-49]. Although there was no report about the connection of auxin and ubiquitin, but the promoter of GLP3b gene has a single putative auxin-response element, which was physically linked to the polyubiquitin 4 gene[50]. In our experiments, we gave evidences that polyubiquitin played a role in both auxin and ABA functions.

\section{ACKNOWLEDGEMENT}

Researches were supported by "the State Key Project of Basic Research, G1999011604” , “Key Project of Knowledge Innovation, CAS" "the National Natural Science Foundation of China, No. 30070073" and "National Sciences Foundation of Pan-Deng” . We thank Prof. Bernd Müller-Röber for helpful comments on the manuscript. Hybridization was performed in the Max-Planck-Institute of Molecular Plant Physiology (Golm, Germany). We thank Prof. Bernd Müller-Röber and Magdalena Ornatowska for help of the performance of hybridization.

\section{REFERENCES}

1 Bray EA. Molecular responses to water deficit. Plant Physiol 1993; 103:1035-40.

2 Jensen AB, Busk PK, Figueras M, Mar Alba, M, Perac-chia G, Messeguer R, Goday A, Pages M. Drought signal transduction in plants. Plant Growth Regulation 1996; 20: 105-10

3 Machuka J, Bashiardes S, Ruben E, Spooner K, Cuming A, Knight C, Cove D. Sequence analysis of expressed sequence tags from an ABA-treated eDNA library identifies stress response genes in the moss physcomitrella patens. Plant Cell Physiol 1999; 40:378-87.

4 Gdmez-Cadenas A, Zentella R, Walker-Simmons MK, Ho, THD. Gibberellin/abscisic acid antagonism in barley aleurone cells: site of action of the protein kinase PKABA1 in relation to gibberellin signaling molecules. The Plant Cell 2001; 13:667-79.

5 Grill E, Himmelbach A. ABA signal transduction. Curr Opin Plant Biol 1998; 1:412-8.

6 Shinozaki K, Yamaguehi-Shinozaki K. Molecular responses to dehydration and low temperature: differences and cross-talk between two stress signaling pathways. Curr Opin in Plant Bio 2000; 3:217-23.

7 McCarty DR, Hattori T, Carson CB, Vasil V, Lazar M, Vasil I. The Viviparous-1 developmental gene of maize encodes a novel transcriptional activator. Cell 1991; 66:895-905.
8 Giraudat J, Hauge B, Valon C, Smalle J, Parcy F, Goodman $\mathrm{H}$. Isolation of the Arabidopsis ABI3 gene by positional cloning. The Plant Cell. 1992; 4:1251-61.

9 Leung 3, Bouvier-Durand M, Morris PC, Guerrier D, Chefdor F, Giraudat J. Arabidopsis ABA response gene ABII: Features of a calcium-modulated protein phosphatase. Science 1994; 264:1448-52.

10 Leung J, Merlot S and Giraudat J. The Arabidopsis ABSCISIC ACID-INSENSITIVE2 (ABI2) and ABI1 genes encode homologous protein phosphatases $2 \mathrm{C}$ involved in abscisic acid signal transduction. The Plant Cell 1997; 9: 759-71.

11 Meyer K, Leube M and Grill E. A protein phosphatase 2C involved in ABA signal transduction in Arabidopsis thaliana. Science 1994; 264:1452-5.

12 Finkelstein RR, Wang ML, Lynch T J, Rao S and Goodman HM. The .Arabidopsis abscisic acid response locus ABI4 encodes an APETALA2 domain protein. The Plant Cell 1998; 10:1043-54.

13 Cutler S, Ghassemian M, Bonetta D, Cooney S and McCourt P. A protein farnesyl transferase involved in abscisic acid signal transduction in Arabidopsis. Science 1996; 273:1239-41.

14 Genoud T, Metraux JP. Crosstalk in plant cell signaling: structure and function of the genetic network. Trends Plant Sci 1999; 4:503-7.

15 Derisi J, Penland L, Brown PO, Bittner ML, Meltzer PS, Ray M, Chen Y, Su YA, Trent JM. Use of a cDNA microarray to analyse gene expression patterns in human cancer. Nature Genetics 1996; 14:457-60.

16 Baldwin D, Crane V, Rice D. A comparison of gel-based, nylon filter and microarray techniques to detect differential RNA expression in plants. Curr Opin Plant Biol 1999; 2:96-103.

17 van Hal NL, Vorst O, van Houwelingen AM, Kok E J, Peijnenburg A, Aharoni A, van Tunen A J, Keijer J. The application of DNA microarrays in gene expression analysis. J Biotech 2000; 78:271-80.

18 Richmond T, Somerville S. Chasing the dream: plant EST microarrays. Curt Opin Plant Biol 2000; 3:108-16.

19 Ye SQ, Lavoie T, Usher DC, Zhang LQ. Microarray, SAGE and their applications to cardiovascular diseases. Cell Res 2002; 12:105-15.

20 Wisman E, Ohlrogge J. Arabidopsis microarray service facilities. Plant Physiol 2000; 124:1468-71.

21 Schena M, Shalon D, Davis RW, Brown PO. Quantitative monitoring of gene expression patterns with a complementary DNA microarray. Science. 1995; 270:467-70.

22 Reymond P, Weber H, Damond M, Farmer EE. Differential gene expression in response to mechanical wounding and insect feeding in Arabidopsis. The Plant Cell 2000; 12:707-20.

23 Girke T, Todd J, Ruuska S, White J, Benning C, Ohlrogge J. Microarray analysis of developing Arabidopsis seeds. Plant Physiol 2000; 124:1570-81.

24 Seki M, Narusaka M, Abe H, Kasuga M, YamaguchiShinozaki K, Carninci P, Hayashizaki Y, Shinozaki K. Monitoring the expression pattern of 1300 Arabidopsis genes under drought and cold stresses by using a fulllength cDNA microarray. The Plant Cell 2001; 13:61-72. 
25 Sambrook J, Fritsch EF, Maniatis T. Molecular Cloning: A laboratory Mannual, 2nd ed., Cold Spring Harbor Laboratory Press, Cold Spring Harbor, NY. 1989.

26 Fieuw S, Müler-Röber B, Galvez S, Willmitzer L. Cloning and expression analysis of the cytosolic $\mathrm{NADP}^{+}$-dependent isocitrate dehydrogenase from potato: implications for nitrogen metabolism. Plant Physiol 1995; 107:90513 .

27 Steinbrenner J, Linden H. Regulation of two carotenoid biosynthesis genes coding for phytoene synthase and carotenoid hydroxylase during stress-induced astaxanthin formation in the green alga Haematococcus pluvialis. Plant Physiol 2001; 125:810-7.

28 Aguan K, Sugawara K, Suzuki N, Kusano T. Low-temperature-dependent expression of a rice gene encoding a protein with a leucine-zipper motif. Mol Gen Genet 1993; 240:1-8.

29 Kim JC, Lee SH, Cheong YH, Yoo CM, Lee SI, Chun H J, Hong JC, Lee SY, Lim CO, Cho MJ. A novel cold-inducible zinc finger protein from soybean, SCOF-1, enhances cold tolerance in transgenic plants. Plant J 2001; 25:247-59.

30 Schenk PM, Kazan K, Wilson I, Anderson JP, Richmond T, Somerville SC, Manners JM. Coordinated plant defense responses in Arabidopsis revealed by microarray analysis. Proc Natl Acad Sci USA 2000; 97:11655-60.

31 Wang R, Guegler K, LaBrie ST and Crawford NM. Genomic analysis of a nutrient response in Arabidopsis reveals diverse expression patterns and novel metabolic and potential regulatory genes induced by nitrate. The Plant Cell 2000; 12:1491-509.

32 Arimura G, Tashiro K, Kuhara S, Nishioka T, Ozawa R, Takabayashi J. Gene responses in bean leaves induced by herbivory and by herbivore-induced volatiles. Biochem Biophys Res Commun 2000; 277:305-10.

33 Luo M, Costa S, Bernacchia G and Cella R. Cloning, characterization of a carrot cDNA coding for a WD repeat protein homologous to Drosophila fizzy, human p55CDC and yeast CDC20 proteins. Plant Mol Biol 1997; 34:325-30.

34 de Vetten N, Quattrocchio F, Mol J, Koes R. The an11 locus controlling flower pigmentation in petunia encodes a novel WD-repeat protein conserved in yeast, plants, and animals. Genes \& Dev 1997; 11:1422-34.

35 Smith TF, Gaitatzes C, Saxena K, Neer EJ. The WD repeat: a common architecture for diverse functions. Trends Biochem Sci 1999; 24:181-5.

36 Hoecker U, Tepperman JM, Quail PH. SPA1, a WD-repeat protein specific to phytochrome A signal transduction.
Science 1999; 284:496-9.

37 Jiang J, Clouse SD. Expression of a plant gene with sequence similarity to animal TGF-beta receptor interacting protein is regulated by brassiuosteroids and required for normal plant development. Plant J 2001; 26:35-45.

38 Alex LA, Simon MI. Protein histidine kinases and signal transduction in prokaryotes and eukaryotes. Trends Genet 1994; 10:133-8.

39 Lau PC, Wang Y, Patel A, Labbe D, Bergeron H, Brousseau R, Konishi Y and Rawlings M. A bacterial basic region leucine zipper histidine kinase regulating toluene degradation. Proc Natl Acad Sci USA. 1997; 94:1453-8.

40 Meyer-zu-Heringdorf D, Lass H, Kuchar I, Lipinski M, Alemany R, Rumenapp U, Jakobs KH. Stimulation of intracellular sphingosine-l-phosphate production by Gprotein-coupled sphingosine-l-phosphate receptors. Eur J Pharmacol 2001: 414:145-54.

41 Grebe TW, Stock JB. The histidine protein kinase superfamily. Adv Microb Physiol 1999; 41:139-227.

42 Crowther GJ, Lynch DV. Characterization of sphinganine kinase activity in corn shoot microsomes. Arch Biochem Biophys 1997; 337:284-90.

43 Nishiura H, Tamura K, Morimoto Y, Imai H. Characterization of sphingolipid long-chain base kinase in Arabidopsis thaliana. Biochem Soc Trans 2000; 28:747-8.

44 Pyne S, Pyne NJ. Sphingosine 1-phosphate signaling in mammalian cells. Biochem J 2000; 349:385-402.

45 Kurkela S, Borg-Franck M. Structure and expression of kin2, one of two cold- and ABA-induced genes of Arabidopsis thaliana. Plant Mol Biol 1992; 19:689-92.

46 Wingler A, Lea P J, Quick WP, Leegood RC. Photorespiration: metabolic pathways and their role in stress protection. Philos Trans R Soc Lond B Biol Sci 2000; 355:1517-29.

47 Finley D, Ozkaynak E, Varshavsky A. The yeast polyubiquitin gene is essential for resistance to high temperatures, starvation, and other stresses. Cell 1987; 48:1035-46.

48 Garbarino JE, Rockhold DR, Belknap WR. Expression of stress-responsive ubiquitin genes in potato tubers. Plant Mol Biol 1992; 20:235-44.

49 Takimoto I, Christensen AH, Quail PH, Uchimiya H, Toki S. Non-systemic expression of a stress-responsive maize polyubiquitin gene (Ubi-1) in transgenic rice plants. Plant Mol Biol 1994; 26:1007-12.

50 Carter C, Graham RA, Thornburg RW. Arabidopsis thaliana contains a large family of germin-like proteins: characterization of cDNA and genomic sequences encoding 12 unique family members. Plant Mol Biol 1998; 38: 929-43. 